\title{
Hyperbaric Oxygen Therapy for the Treatment of Acute Cochlear Disorders and Tinnitus
}

\author{
Kerstin Lamm \\ Clinic for Otolaryngology, Head and Neck Surgery, Klinikum rechts der Isar, Technical University of Munich, \\ Munich, Germany
}

Hyperbaric oxygen (HBO) has been successfully used in otology for the treatment of acute acoustic trauma, acute noise-induced hearing loss, idiopathic sudden sensorineural hearing loss (SNHL) and other acute cochlear disorders with or without tinnitus for as many as 35 years [for a review, see 1]. In most clinical trials, HBO was administered only when conventional initial therapy using various drugs, such as rheologically active drugs, plasma expander, vasodilators or glucocorticoids, had failed. A meta-analysis of 50 clinical studies carried out on a total of 4,109 patients who received HBO therapy following unsuccessful conventional treatment with drugs has shown that - providing the onset of disorder was longer than 2 weeks but not longer than 6 weeks $-50 \%$ of patients experienced a marked hearing improvement in at least 3 frequencies of $20 \mathrm{~dB}$ or more, one third of patients showed a moderate improvement $(10-20 \mathrm{~dB})$ and $13 \%$ of patients did not show any improvement at all [1]. In addition, $4 \%$ no longer suffered from tinnitus, $81.3 \%$ observed a decrease in tinnitus intensity and $1.2 \%$ a temporary increase in tinnitus intensity, whereas $13.5 \%$ revealed their condition to be unchanged [1]. These results were confirmed in current studies [2-6].

Recently four studies have been published on the effect of an initial HBO therapy for the treatment of SNHL [710]. Flunkert et al. [7] have found that hearing improve- ment and the effect on tinnitus after initial HBO therapy were similar compared to the effects of infusion therapy with a plasma expander and vasodilator. Similarly, Kestler et al. [8] revealed no better results after initial HBO therapy than those published in the literature after infusion therapy with a plasma expander which, in turn, did not surpass the rate of spontaneous remission published in the literature. In contrast, Fattori et al. [9] concluded that HBO should be considered the preferred treatment, since significantly more patients experienced a significantly greater hearing improvement in the HBO group as compared to the vasodilator-treated group. Aslan et al. [10] revealed a significantly greater mean hearing gain (37.9 dB) after combined treatment with HBO, glucocorticoids (prednisone) and betahistine compared to patients who received the drugs without HBO $(20 \mathrm{~dB})$. The authors concluded that the addition of HBO to conventional treatment significantly improves the outcome of SNHL, especially in patients younger than 50 years, but not in patients older than 60 years.

In the present issue, Racic et al. publish a retrospective clinical trial on 115 patients suffering from SNHL: 51 patients were primarily treated with $\mathrm{HBO}$ and 64 patients with infusions of a rheological drug (pentoxifylline) 1 week after onset of hearing loss. Both groups did not differ from each other respecting e.g. age, sex or initial hearing

\begin{tabular}{ll}
\hline KARGER & $\begin{array}{l}\text { (c) 2003 S. Karger AG, Basel } \\
\text { 0301-1569/03/0656-0315\$19.50/0 }\end{array}$ \\
$\begin{array}{l}\text { Fax +4161306 12 34 } \\
\begin{array}{l}\text { E-Mail karger@karger.ch } \\
\text { www.karger.com }\end{array}\end{array}$ & $\begin{array}{l}\text { Accessible online at: } \\
\text { www.karger.com/orl }\end{array}$
\end{tabular}

Prof. Kerstin Lamm, MD, PhD

Technical University of Munich, Klinikum rechts der Isar

Clinic for Otolaryngology, Head and Neck Surgery, Ismaninger Strasse 22

DE-81675 München (Germany)

Tel. +49 894140 4191, Fax +49 894140 4992, E-Mail k.lamm@lrz.tum.de 
loss. The mean hearing gain in the HBO group was $46 \mathrm{~dB}$ versus $21 \mathrm{~dB}$ in the pentoxifylline group. This difference was statistically highly significant $(p<0.001)$. Furthermore, in the HBO group hearing recovered to physiological levels in 24/51 (47\%) patients, whereas only 4/64 (6\%) completely recovered in the pentoxifylline group. In addition, after HBO therapy 21/51 (41\%) patients improved significantly (up to a mild persistent hearing loss), whereas this was the case in only $8 / 64(12 \%)$ pentoxifyllinetreated patients. In summary, 45/51 (88.3\%) HBOtreated patients and only $12 / 64(12.7 \%)$ pentoxifylline- treated patients recovered completely or partially. A follow-up examination after 9 months confirmed these results, indicating a persistent therapeutic effect of HBO. The present results after pentoxifylline therapy are in accordance with Probst et al. [11] who have proved that pentoxifylline therapy induced an equal mean hearing gain $(15.6 \mathrm{~dB})$ as saline infusions and placebo tablets $(22.7 \mathrm{~dB})$ in SNHL.

Altogether, these results indicate strong evidence that initial HBO therapy is more effective in the treatment of SNHL than conventional rheological therapy.

\section{References}

1 Lamm K, Lamm H, Arnold W: Effect of hyperbaric oxygen therapy in comparison to conventional or placebo therapy or no treatment in idiopathic sudden hearing loss, acoustic trauma, noise-induced hearing loss and tinnitus: A literature survey; in Yanagita N, Nakashima T (eds): Hyperbaric Oxygen Therapy in Otorhinolaryngology. Adv Otorhinolaryngol. Basel, Karger, 1998, vol 54, pp 86-99.

2 Kau RJ, Sendtner-Gress K, Ganzer U, Arnold W: Effectiveness of hyperbaric oxygen therapy in patients with acute and chronic cochlear disorders. ORL 1997:59:79-83.

3 Nakashima T, Fukuta S, Yanagita N: Hyperbaric oxygen therapy for sudden deafness; in Yanagita N, Nakashima T (eds): Hyperbaric Oxygen Therapy in Otorhinolaryngology. Adv Otorhinolaryngol. Basel, Karger, 1998, vol 54 pp 100-109.
4 Shiraishi T, Satou Y, Makashima K: Hyperbaric oxygenation therapy in idiopathic sudden sensorineural hearing loss. Nippon Jibiinkoka Gakkai Kaiho 1998;101:1380-1384.

5 Delb W, Muth CM, Hoppe U, Iro H: Ergebnisse der hyperbaren Sauerstofftherapie bei therapieresistentem Tinnitus. HNO 1999;47: 1038-1045.

6 Murakawa T, Kosaka M, Mori Y, Fukazawa M, Misaki K: Treatment of 522 patients with sudden deafness performed oxygenation at high pressure. Nippon Jibiinkoka Gakkai Kaiho 2000;103:506-515.

7 Flunkert C, Schwab B, Heermann R, Lenarz T: Hyperbare Sauerstofftherapie als Primärtherapie akuter Innenohrschädigungen - Abschlussergebnisse einer prospektiven randomisierten Studie. Mitt Norddtsch Ges Otorhinolaryngol Zervikofaz Chir 2001;23:28-31.
8 Kestler M, Strutz J, Heiden C: Hyperbare Oxygenation in der Frühbehandlung des Hörsturzes. HNO 2001;49:719-723.

9 Fattori B, Berrettini S, Casani A, Nacci A, De Vito A, De Iaco G: Sudden hypoacusis treated with hyperbaric oxygen therapy: A controlled study. Ear Nose Throat J 2001;80:655-660.

10 Aslan I, Oysu C, Veyseller B, Baserer N: Does the addition of hyperbaric oxygen therapy to the conventional treatment modalities influence the outcome of sudden deafness? Otolaryngol Head Neck Surg 2002;126:121-126.

11 Probst R, Tschopp K, Ludin E, Kellerhals B, Podvinec M, Pfaltz CR: A randomized, double-blind, placebo-controlled study of dextran/ pentoxifylline medication in acute acoustic trauma and sudden hearing loss. Acta Otolaryngol 1992;112:435-443. 